\title{
MANAGEMENT OF A T-TUBE MIGRATION INTO THE SYRINX CAVITY: A CASE REPORT
}

\author{
Ceren Yılmaz $^{1}$ (D), Erkan Sebici ${ }^{1}$ (D), Mert Yücel Ayrık ${ }^{1}$ (D), \\ Ahmet Hamit Çınkı ${ }^{2}$ (D, Ahmet Tolgay Akıncı ${ }^{2}$ (D) \\ ${ }^{1}$ Trakya University School of Medicine, Edirne, TURKEY \\ ${ }^{2}$ Department of Neurosurgery, Trakya University School of Medicine, Edirne, TURKEY
}

\begin{abstract}
Aims: To present a rare syringomyelia case that necessitated a revision surgery because of a T-tube migration into the syrinx cavity. Case Report: A 53-year-old female patient was presented with progressive pain in the right arm and numbness in the neck. She had undergone decompression and stabilization surgery at the T6-T9 levels four years ago. One year later, she underwent a T-tube placement operation for syringomyelia. She remained relatively stable until the latest admission. A detailed neurological examination revealed no difference compared to her previous neurological condition. Computerized Tomography and Magnetic Resonance Imaging scans demonstrated that the syrinx had expended and the T-tube had migrated into the syrinx cavity. A revision was carried out, the migrated T-tube was removed through fenestration, and a new T-tube was placed. Her condition had significantly improved at follow-up, and the syrinx had markedly regressed. Conclusion: Syringosubarachnoid shunting operations might lead to rare complications such as T-tube migration, which necessitate revision surgery. Nearly complete relief of symptoms can be achieved with successful revision surgery. Keywords: Syringomyelia, revision, surgery
\end{abstract}

\section{INTRODUCTION}

Syringomyelia disease defined by the formation of fluid-filled longitudinal spaces (syrinx) in the spinal cord (1). These can expand and elongate over time, causing several symptoms that may vary depending on the area where the syrinx is applying pressure on the spinal cord (2). Therefore, patients may experience different combinations of the following symptoms: pain, weakness, stiffness in the back, shoulders, and extremities, and inability to distinguish hot and cold. Syringomyelia may occur due to hydrocephalus, Chiari malformation, tumors, spinal canal stenosis, and trauma, although many cases remain idiopathic $(2,3)$.

Posttraumatic syringomyelia (PTS) results from severe spinal cord injuries such as those from traffic accidents or falls from heights. PTS incidence varies between $1 \%$ - 7\% (4). Patients are prone to neurological deterioration, for such cases, syringosubarachnoid shunting surgery is one of the treatments of choice $(4,5)$. Syringosubarachnoid shunting operations, like other shunting procedures, might have many complications. We present a rare syringomyelia case that necessitated a revision surgery because of a migrated T-tube into the syrinx cavity.

\section{CASE REPORT}

A 53-year-old female patient was presented with progressive pain in the right arm and numbness in the neck. Her medical history included a car accident four years ago, causing a thoracic fracture-dislocation at T7-T8 resulting in paraplegia. She had undergone spinal surgery including the decompression and the stabilization of the T6-T9 levels (Figure 1). 10 months after the accident she was admitted with contractions in the arms and legs, syringomyelia ascending to the upper cervical region was found, and a thoracic syringosubarachnoid shunting surgery that included T-tube insertion into the syrinx cavity was performed (Figure 2). She remained relatively stable until her admission with progressive pain in the right arm and numbness in the neck.

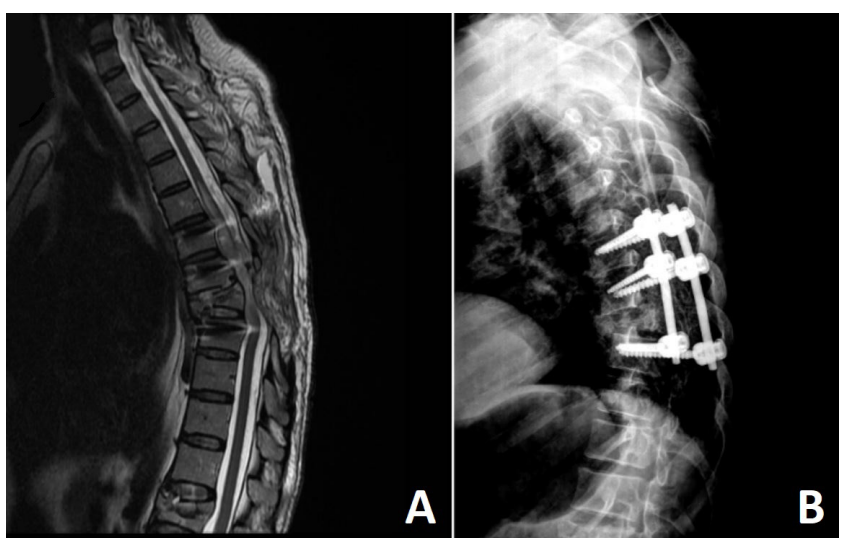

Figure 1: Images after the decompression and stabilization surgery of T6-T9 levels. A: Sagittal T2-weighted magnetic resonance image. B: Sagittal X-Ray image.

A neurological examination revealed no difference compared to her neurological condition following the spinal cord injury; there were no motor deficits in upper extremities, mild hypoesthesia in both arms and neck, total anaesthesia below the Th10 dermatome, and total paraplegia along with urinary and fecal incontinence. 
Computerized Tomography and Magnetic Resonance Imaging scans demonstrated that the T-tube had migrated into the syrinx cavity and the syrinx had progressed (Figure 3 ).

A revision surgery, including a central canal fenestration at the same location as the previous shunting surgery, was planned and carried out. During the revision surgery, the migrated T-tube was identified and removed through the fenestration (Figure 4). A new T-tube was placed through the same fenestration and fixed (Figure 5). The postoperative period was uneventful. At the sixth month follow-up, her symptoms had improved significantly, and the syrinx had markedly regressed (Figure 6).

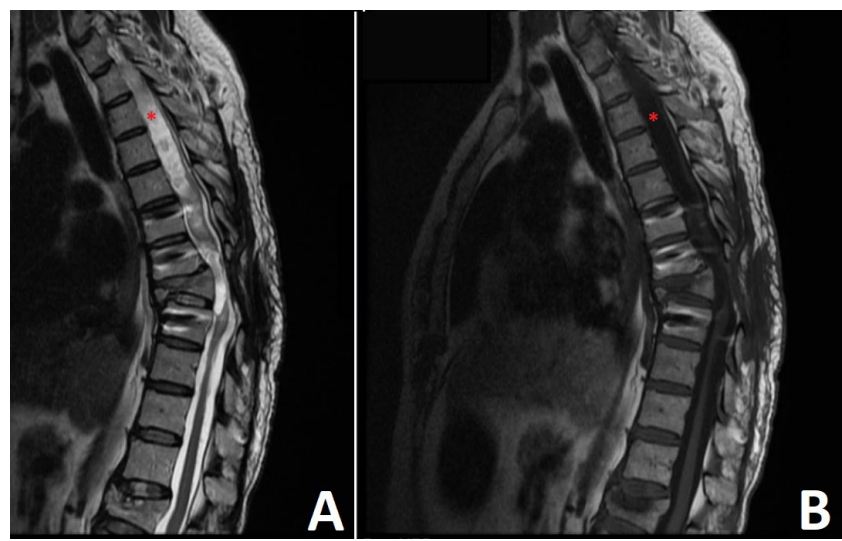

Figure 2: Syringomyelia that progresses to the cervical region (shown with asterisks). A: Sagittal T2 weighted magnetic resonance image. B: Sagittal T1 weighted magnetic resonance image.
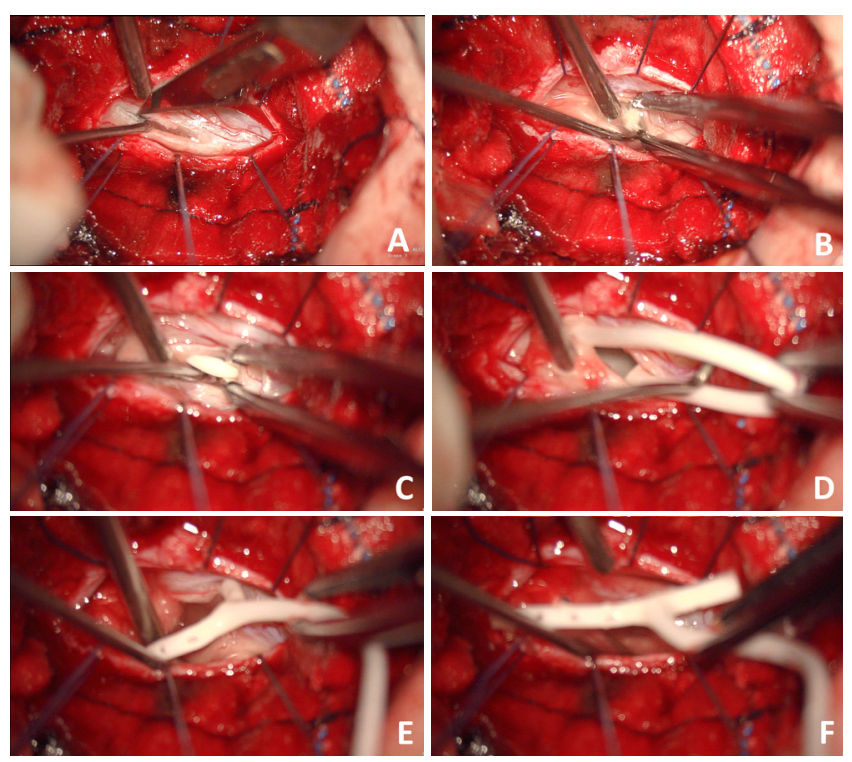

Figure 4: A-F: The stages of the operation in which the T-tube is removed.
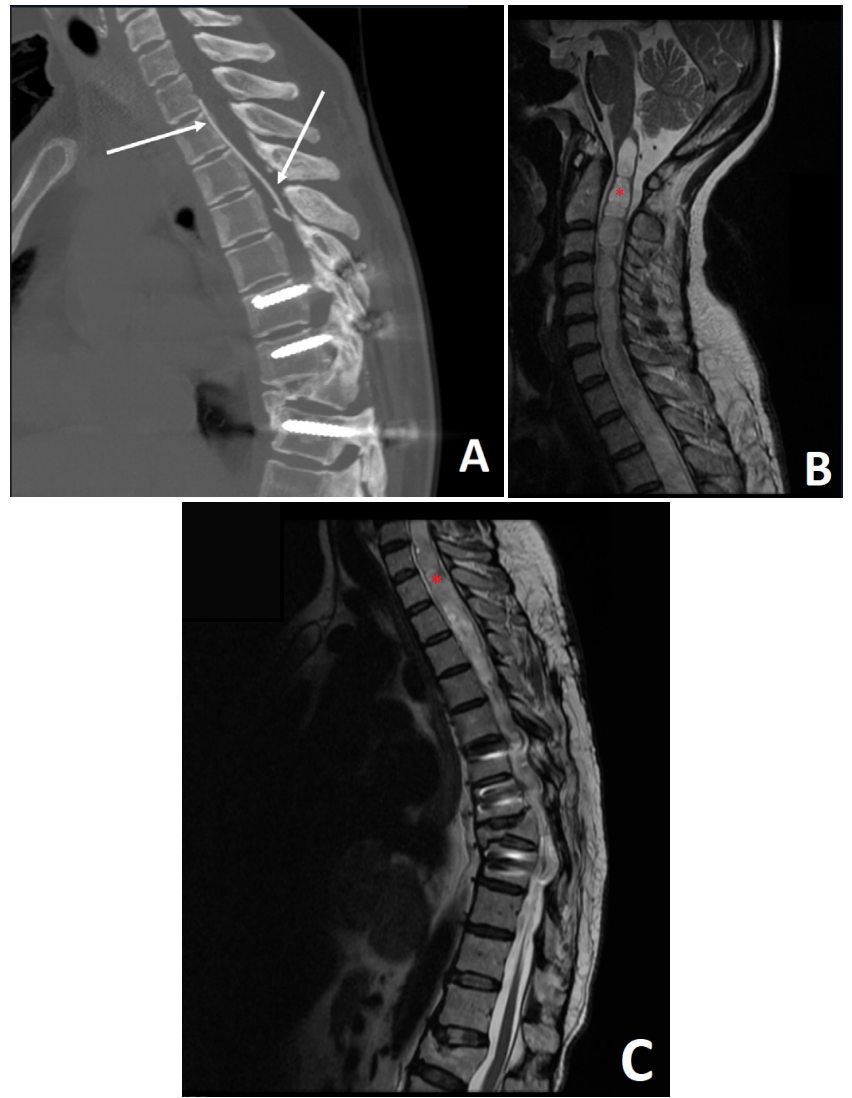

Figure 3: A: Reconstructed sagittal bone window CT scan image of the migrated T-tube into the syrinx cavity (shown with arrows). $B, C$ : Cervical and thoracal sagittal T2 weighted magnetic resonance images of the syringomyelia that progresses to the upper cervical region (shown with asterisks).

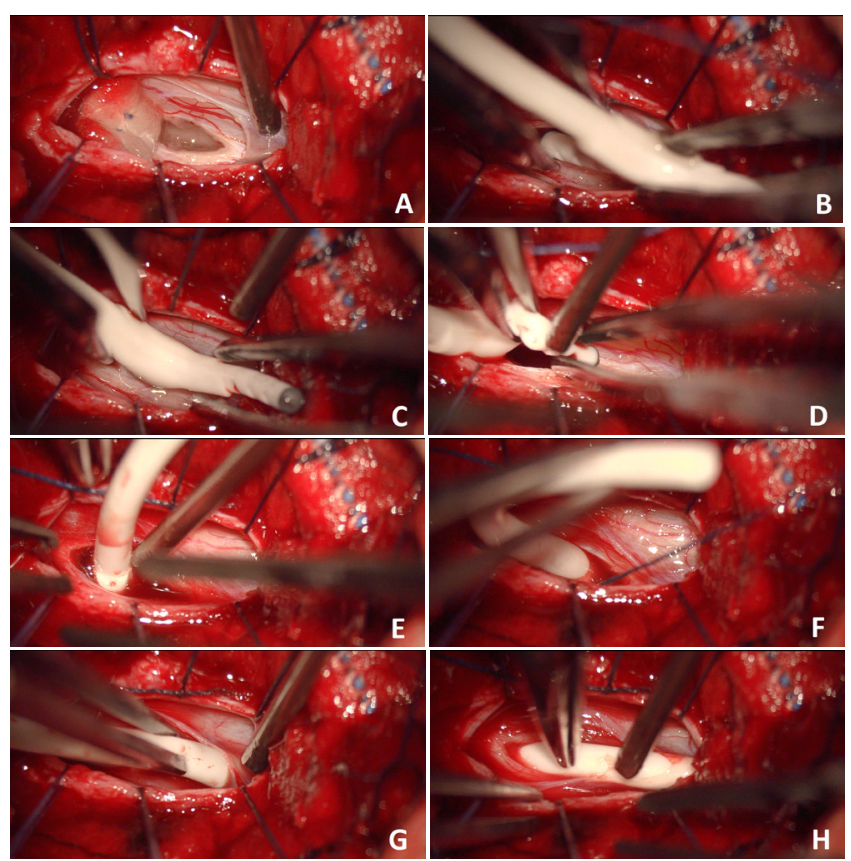

Figure 5: A-H: The stages of the new T-tube insertion process. 


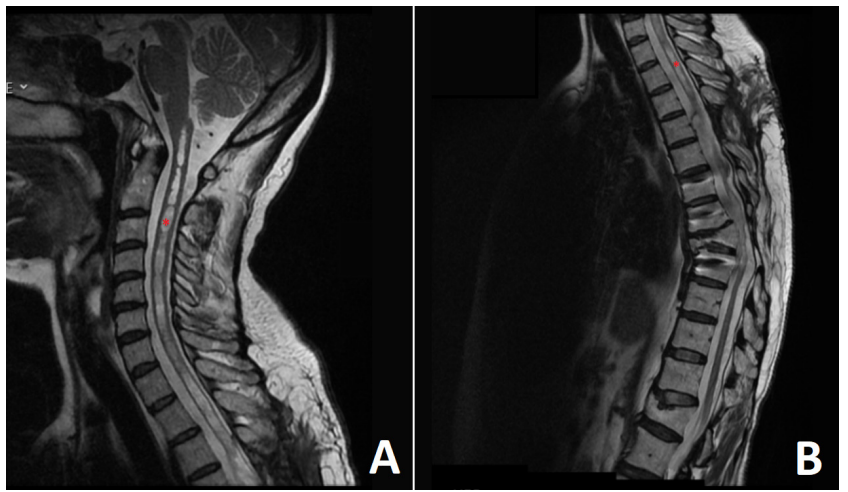

Figure 6: A, B: Cervical and thoracal sagittal T2 weighted magnetic resonance images of the syringomyelia regressed at 6th-month follow-up (shown with asterisks).

\section{DISCUSSION}

As syringomyelia is treated as a secondary phenomenon, rather than a primary spinal cord disease, not all cystic changes in the spinal cord are syringomyelia related. Therefore, the diagnosis of syringomyelia requires the identification of its cause (6). By definition, PTS is distinguished by an antecedent trauma.

An analysis of 138 patients with PTS by Krebs et al. (4) reported the syringomyelia in the cervicothoracic region in 58 patients (42\%), in thoracic region in 50 patients $(36.2 \%)$, in the cervical region in 19 patients $(13.8 \%)$, and in the thoracolumbar region in 5 patients (3.6\%). Furthermore, syringomyelia was detected at an average age of 42 years, a median of 15 years after the spinal cord injury. In the presented case, the patient was 53-year-old and diagnosed with syringomyelia in the thoracic region, ten months after the spinal cord injury.

There are various options for the surgical treatment of PTS, such as decompression, fenestration, bypass, and shunting procedures (7-10). For procedures that do not include the implantation of a tube, generally, the spinal cord is untethered from the dura by dismembering arachnoid adhesions, and one or multiple fenestrations are performed to the cyst from single or multiple openings (7). Hayashi et al. (8) investigated the results of a bypass surgery by connecting cranial and caudal normal subarachnoid spaces via tubes in 20 patients and reported that 12 patients showed clinical improvement, while four patients remained stable, and four deteriorated.

Shunting procedures include syringopleural, syringoperitoneal, and syringosubarachnoid shunting operations (5, 7-10). For syringomyelia, subarachnoid shunt is one of the treatments of choice and for patients with neurological deterioration, it is a safe and effective treatment (5). Karam et al. (3), in their study consisting of 27 PTS patients in total found that 10 of the 16 patients, on whom the performed surgery was the shunt alone, required revision surgery, while 3 of the 11 patients whose surgery included duroplasty, lysis of adhesions and shunting, required revision surgeries due to the lack of decrease in syringomyelia size and failure to improve the symptoms. Aghakhani et al. investigated the effectiveness of shunting and arachnoidolysis procedures in 34 patients. They reported that syringomyelia recovered or stabilized in $94 \%$ of the patients after arachnoidolysis and the spinal cord's untethering. They have also reported that shunting resulted in a higher risk of reoperation due to a higher recurrence (11).
In the presented case revision surgery was performed due to the T-tube's migration into the central canal. Since the patient had paraplegia, a more extensive fenestration and removal of the migrated T-tube were more comfortable to perform. Subsequently, a new T-tube was placed through the fenestration. During the follow-up, her symptoms had relieved significantly.

To conclude, a syringosubarachnoid shunt using a T-tube is an effective treatment option for PTS, although complications, including rare ones such as tube migration, might occur. In such cases, revision surgery is inevitable. In the revision surgery, when feasible, the new tube may be inserted using the same fenestration that was used to remove the dislocated tube. Successful revision surgery may improve the symptoms to a great extent.

Ethics Commitee Approval: N/A

Informed Consent: Written informed consent was obtained from the patient for this study.

Conflict of Interest: The authors declared no conflict of interest.

Author contributions: Concept: CY, ES, MYA, AÇ, ATA. Design: CY, ES, MYA, AÇ, ATA. Supervision: CY, ES, MYA, AÇ, ATA. Resources: CY, ES, MYA, AÇ, ATA. Materials: CY, ES, MYA, AÇ, ATA. Data collection and/ or processing: CY, ES, MYA, AÇ, ATA. Analysis and/or interpretation: CY, ES, MYA, AÇ, ATA. Literature search: CY, ES, MYA, AÇ, ATA. Writing manuscript: CY, ES, MYA, AÇ, ATA. Critical review: CY, ES, MYA, AÇ, ATA. Financial disclosure: The authors declared that this study received no financial support.

Editor-in-chief 's Note: One author of this article, Mert Yücel Ayrık is a member of the editorial board of Turkish Medical Student Journal. However, he did not take place in any stage of the editorial decision of the manuscript. The editors who evaluated this manuscript are from other institutions.

\section{REFERENCES}

1. Greitz D. Unraveling the riddle of syringomyelia. Neurosurg Rev 2006;29(4):25163.

2. Vandertop WP. Syringomyelia. Neuropediatrics 2014;45(1):3-9.

3. Karam Y, Hitchon PW, Mhanna NE et al. Post-traumatic syringomyelia: Outcome predictors. Clin Neurol Neurosurg 2014;124:44-50.

4. Krebs J, Koch HG, Hartmann K et al. The characteristics of posttraumatic syringomyelia. Spinal Cord 2016;54(6):463-6.

5. Davidson KA, Rogers JM, Stoodley MA. Syrinx to subarachnoid shunting for syringomyelia. World Neurosurg 2018;110:e53-e59.

6. Klekamp J. How should syringomyelia be defined and diagnosed? World neurosurgery 2018;111:e729-e745.

7. Levi AD, Sonntag VK. Management of posttraumatic syringomyelia using an ex pansile duraplasty: A case report. Spine 1998;23(1):128-32.

8. Hayashi T, Ueta T, Kubo $\mathrm{M}$ et al. Subarachnoid-subarachnoid bypass: A new surgical technique for posttraumatic syringomyelia. J Neurosurg Spine 2013;18(4):382-7.

9. Williams B, Page N. Surgical treatment of syringomyelia with syringopleural shunting. Br J Neurosurg 1987;1(1):63-80.

10. Barbaro NM, Wilson CB, Gutin PH et al. Surgical treatment of syringomyelia: Favorable results with syringoperitoneal shunting. J Neurosurg 1984;61(3):531-8.

11. Aghakhani N, Baussart B, David P et al. Surgical treatment of posttraumatic syringomyelia. Neurosurgery 2010;66(6):1120-7. 